\title{
O DISCURSO DO TRABALHO E SUAS MÚLTIPLAS EXPRESSÕES MATERIAIS E IDEOLÓGICAS ${ }^{1}$
}

\author{
MARIA VIRGÍNIA BORGES AMARAL ${ }^{2}$
}

Programa de Pós-Graduação em Linguística e Literatura

Faculdade de Letras, Campus A. C. Simões, Universidade Federal de Alagoas

Av. Lourival Melo Mota, S/N, Tabuleiro do Martins - 57072-970 - Maceió, AL - Brasil

mvirginia39@gmail.com

\begin{abstract}
Resumo. $O$ discurso do trabalho se movimenta numa dinâmica contraditória para se conformar às necessidades do capitalismo. Vê-se nos discursos que materializam formações ideológicas do trabalho e do capital uma tensão entre os sentidos de "trabalho" e "emprego". Este estudo apresenta uma reflexão sobre os discursos do trabalho e do emprego, focalizando o processo de expropriação do trabalho que atingiu os trabalhadores na sociedade moderna. Analisa esse acontecimento discursivo com base no materialismo histórico, ressaltando a natureza dialética do discurso de expropriação. Recupera materialidades do acontecimento das reformas trabalhistas recentemente aprovadas no Brasil para demonstrar como, na continuidade do processo, os trabalhadores perderam o trabalho, estão perdendo o emprego e o sentido de classe.
\end{abstract}

Palavras-chave: discurso; acontecimento discursivo; trabalho; emprego; expropriação.

\begin{abstract}
The labour discourse moves in a contradictory dynamic in order to conform itself to the needs of capitalism. What can be seen in discourses that materialize the labour and the capital ideological formations is a tension between the senses of "labour" and "employment." This study presents a reflection regarding the discourses of labour and employment, focusing on the expropriation process of labour that has affected workers in modern society. It analyzes this discursive event based on the historical materialism, highlighting the dialectic nature of the expropriation discourse. The article retrieves materialities from the event of the recently approved labour reforms in Brazil to demonstrate how, in the continuity of such process, workers have lost their labours, are losing jobs and the sense of class.
\end{abstract}

Keywords: discourse; discursive event; labour; employment; expropriation.

\footnotetext{
${ }^{1}$ Agradecemos ao CNPq pelo apoio às nossas pesquisas.

${ }^{2}$ Docente e pesquisadora na Graduação e na Pós-graduação em Serviço Social e em Letras e Linguística, na UFAL. Atua no Programa de Pós-Graduação de Letras e Linguística na mesma instituição.
} 


\section{INTRODUÇÃO}

A contradição não pode ser eliminada do discurso. No discurso, tudo é movimento, retomada, reorientação, reconfiguração, confronto, atualidade e memória, produção do aparentemente novo. O discurso é processo; é e faz história. Tanto pode confortar como pode afligir; depende da sociedade e do momento histórico em que é produzido. $\mathrm{O}$ discurso é acontecimento, como entende Pêcheux (1990, p. 17): "um ponto de encontro de uma atualidade e uma memória". O discurso é um processo não homogêneo, marcado por uma desestruturação-reestruturação das redes de trajetos históricos que ele irrompe, uma discursivização do acontecimento que implica o acontecimento discursivo, assim como diz Rassi (2014, p. 43): "para que um acontecimento discursivo surja como tal, é preciso que alguém o crie". E mais: "o acontecimento discursivo não coincide com a notícia jornalística nem com os registros de um fato na história, pois se trata de um gesto de leitura, é uma das formas de se ver o mesmo dado/fato" (p. 46).

O discurso do trabalho e suas múltiplas expressões é objeto deste estudo e, para realizar a análise a qual nos propomos, começamos por apresentar a natureza contraditória do discurso, compreendido como uma materialidade da ideologia, portanto uma materialidade ideológica. Disto decorre a necessidade de indicar que a questão ideológica no campo da Análise do Discurso à qual filiam-se as orientações teóricas deste estudo é examinada à luz do materialismo histórico.

Importa dizer, a partir da perspectiva do materialismo histórico que por meio da ideologia, as sociedades divididas em classes enfrentam conflitos decorrentes de seus interesses antagônicos. Então, a ideologia é instrumento de luta e serve para fortalecer interesses das duas classes fundamentais ${ }^{3}$ da sociedade capitalista. Esta é a qualidade social da ideologia: desempenhar uma função junto às lutas sociais com a pretensão de controlar os conflitos sociais e preservar a ordem, "recrutando" os indivíduos em sujeito 4 . Pêcheux e Fuchs (1993b, p. 166), ao analisarem a função social da Ideologia, a partir da teoria de Althusser dos Aparelhos Ideológicos do Estado (1970) - "a ideologia interpela os indivíduos em sujeitos" -, consideram que essa função se realiza mediada pela formação ideológica que "constitui um conjunto complexo de atitudes e de representações que não são nem 'individuais' nem 'universais', mas se relacionam mais ou menos diretamente a posições de classes em conflito umas com as outras". O discurso é, assim, identificado como a "materialidade ideológica"; é a forma, a concretude que a formação ideológica toma para intervir no "conjunto complexo de atitudes e representações" que, como lembram os autores referidos, dizem respeito às "práticas no sentido marxista" (PÊCHEUX; FUCHS, 1993, p. 237, nota 7).

\footnotetext{
${ }^{3}$ Assim como define Marx, ao concluir que, na sociedade capitalista, devido à propriedade privada, as classes sociais restringiram-se em duas: "O resultado final, portanto, é a abolição da distinção entre capitalista e grande proprietário de maneira que, ao todo, há apenas duas classes de população, a classe trabalhadora e a classe capitalista" (MARX, 1989, 150).

${ }^{4}$ Disto decorre, conforme identificamos em nossas análises, como veremos adiante, o processo de recrutamento na sociedade capitalista de todos os homens trabalhadores em empregados trabalhadores ou trabalhadores informais (por conta própria). Lembremos Pêcheux (1996, p. 151): "se é verdade que a ideologia "recruta" sujeitos entre os indivíduos (à maneira como os soldados são recrutados entre os civis), e que os recruta a todos, precisamos saber de que modo os "voluntários" são designados nesse recrutamento, isto é, no que diz respeito, como os indivíduos aceitam como evidente o sentido daquilo que ouvem e dizem, leem e escrevem (ou do que tencionam dizer e do que se tenciona dizer a ele), na condição de 'sujeito falante'[...]".
} 
$\mathrm{Na}$ medida em que o discurso é uma materialidade da ideologia, ele também é um complexo de sentidos no qual o texto, o dito (aparência) oculta a memória discursiva ${ }^{5}, o$ não-dito (a essência). Assim, é possível afirmar que o caráter contraditório da ideologia é extensivo a todo e qualquer discurso. Isso implica a compreensão de que a "forma social ativa" da ideologia é o discurso: ele é a materialidade que concretiza a função social da ideologia; é uma unidade da diversidade, uma "síntese de múltiplas determinações", "concreto pensado" (MARX, 1983), "objeto concreto" (COURTINE, 2006, p. 65). O discurso é um complexo contraditório composto por processos que revelam e, ao mesmo tempo, ocultam a realidade, afirmando-se e negando-se, neste jogo tenso entre contrários.

Procuraremos demonstrar como o movimento contraditório (dialético) do discurso funciona no processo de produção/deslocamentos dos sentidos de trabalho e emprego em discursos, cuja materialidade linguística se dilui na "discursivização do acontecimento". Serão analisadas materialidades de acontecimentos recentes do discurso do trabalho, particularmente no Brasil, a partir das reformas trabalhistas de 2016. Neste estudo, faz-se uma discussão sobre os discursos do trabalho e do emprego, focalizando o processo de expropriação do trabalho que atinge os trabalhadores desde o advento da sociedade moderna. A análise é feita com base no materialismo histórico, ressaltando a natureza dialética que permite entender a extensão da ideologia no discurso.

Nessa linha de pensamento, é possível proceder aproximações da "esfera profunda (ontológica)" do discurso para conhecer o movimento que o faz interferir na realidade, produzindo sentidos que aparecem harmonizados, mas ocultam uma tensão entre ruptura e continuidade, mesmo e diferente, memória e atualidade indicando um acontecimento neste ponto de encontro. "Penetrar" na esfera profunda do discurso do trabalho, a sua memória discursiva, é o propósito da análise para que se chegue à compreensão das razões (subjetivas e objetivas) que regulam o processo de expropriação do trabalho. No processo de absorção do trabalho pelo emprego, desloca-se/oculta-se o sentido de trabalho concreto $^{6}$ em função da primazia do trabalho abstrato, até que o trabalhador seja ressignificado como mercadoria, força de trabalho, ser assalariado, pondo-se um novo modo de ser deste na produção capitalista.

O fetiche de felicidade propagado no discurso do capitalismo moderno, que opera silenciando a expropriação do trabalho, ascendendo o emprego como compensação e, depois, aniquilando-o com o discurso da "autonomia" do trabalhador expressa a contradição do discurso do capitalismo. Enquanto cria mecanismos discursivos para produzir efeitos de esperança, de dias melhores para o trabalhador, "abafa" e silencia a realidade da produção capitalista desta época que dispensa os trabalhadores, desmobiliza-

\footnotetext{
${ }^{5}$ A noção de memória discursiva está ancorada em Pêcheux (1999, p. 52) que revela a sua complexidade, considerando-a para além daquilo "[...] que face a um texto que surge como acontecimento a ler, vem restabelecer os "implícitos" (quer dizer, mais tecnicamente, os pré-construídos, elementos citados e relatados, discursos transversos etc.) de que sua leitura necessita [...]". Pêcheux questiona: "A questão é, saber onde residem esses famosos implícitos [...]: estão eles disponíveis na memória discursiva como um fundo de gaveta, um registro oculto?" Pêcheux (p. 56) indica que há "o outro interno em toda memória" que é, ao seu ver, "a marca do real histórico como remissão ao outro exterior, [...] ao real histórico como causa do fato de que nenhuma memória pode ser um frasco sem exterior (p. 56).

${ }^{6}$ A partir da mercadoria, Marx (1988) identifica a dupla realidade do trabalho na produção capitalista: "trabalho concreto" - que se realiza no valor de uso - e "trabalho abstrato" - que se realiza no valor de troca. Diz ele: "Para criar mercadoria, é mister não só produzir valor de uso, mas produzi-lo para outros, dar origem a valor de uso social" (p. 48), isto é, dar origem a valor de troca.
} 
os e os coloca mais longe do sentido de classe num processo de desmemória, um conceito proposto por Paveau (2015, p. 236) do qual nos aproximamos para identificar o processo de desancoragem/ancoragem do sentido de trabalho do seu contexto referencial original. Para Paveau, desmemória discursiva é "um conjunto de fenômenos de disjunção dessas evocações e inserções no fio memorial do discurso". Ao longo deste estudo, poderemos perceber esse funcionamento dialético do discurso do trabalho: a tentativa do discurso do capital em apagar da memória discursiva o trabalho no discurso do emprego e, ao mesmo tempo, fazê-la subsistir para dar sentido a novas modalidades de produção capitalista.

\section{SOBRE O DIREITO DO/AO TRABALHO NA HISTÓRIA}

Sabe-se que a história dos direitos está associada à história das sociedades que se estruturam sobre o domínio do capital; nelas, o Estado produz discursos que simulam evidências de representação de interesses comuns; apresenta-se como expressão da lei e da proteção aos sujeitos. Destas assertivas, decorrem, neste estudo, três pontos fundamentais ao andamento das reflexões a seguir:

1. A sociedade do capital produziu o trabalho assalariado, requisitando a intervenção do Estado para estabelecer formas de controle dos "contratos" nas relações de trabalho.

2. Os contratos tornaram o assalariamento legal e o capital pôde controlar o trabalho, criando simulacros de liberdade para o trabalhador trocar o seu trabalho por salário (emprego).

3. A sociedade capitalista simula evidências de igualdade, normatiza o direito ao trabalho sob bases econômicas e sociais; define o trabalho como o direito de todos, enquanto rompe com os contratos e deixa o trabalhador, que teve seu trabalho/emprego subtraído, ao relento.

É interessante lembrar que o "direito ao trabalho" nas sociedades de classe está incluído entre os direitos fundamentais porque foram valorados pela sociedade em um dado momento histórico para serem dirigidos a todos os indivíduos, sem restrições de raça, credo, ou convicções políticas (PEREIRA; RANGEL, 2019). Assim está prescrito na Declaração Universal dos Direitos Humanos adotada e proclamada pela resolução 217 A (III) da Assembleia Geral das Nações Unidas, em 10 de dezembro de 1948, no artigo 23ㅜ, do qual destacamos os parágrafos 1 e 3: 1. "Toda pessoa tem direito ao trabalho, à livre escolha do trabalho, a condições equitativas e satisfatórias de trabalho e à proteção contra o desemprego". 3. "Toda pessoa tem o direito de fundar com outras pessoas sindicatos e de se filiar em sindicatos para defesa dos seus interesses" (UNESCO/Brasil 1948 [1998]).

No Brasil, a Constituição Brasileira de 1988 prescreve o direito ao trabalho e ao salário (portanto, ao emprego, como veremos) que garanta a subsistência do trabalhador e de seus familiares; essa é uma obrigação da sociedade capitalista que deveria ser garantida pelo Estado. Do artigo $7^{\circ}$ ao artigo $11^{\circ}$, estão prescritos os principais direitos para os trabalhadores. Lembremos o artigo $7^{\text {0: }}$ "são direitos dos trabalhadores urbanos e rurais, além de outros que visem à melhoria de sua condição social: XXX - proibição de diferença de salários, de exercício de funções e de critérios de admissão por motivo de sexo, idade, cor ou estado civil" (Constituição da República Federativa do Brasil, 1988 [2012]). Neste país, "direito do trabalho" é normatizado pelo Estado por meio de um 
documento legal que consolida esse direito, como o próprio título revela: Consolidação das Leis Trabalhistas - CLT. A primeira versão desse documento foi aprovada pelo Presidente da República Getúlio Vargas por meio do Decreto-Lei $n^{\circ} 5.452$, de $1^{\circ}$ de maio de 1943 (hoje data comemorativa do trabalho).

Do ano em que a CLT foi publicada até os dias atuais, a forma do documento sofreu inúmeras retificações, mas sua essência é a mesma: consolidar as leis trabalhistas, observar e fazer valer as determinações da lei, acompanhar as mudanças do capitalismo e suas exigências para com o trabalho. A mudança mais recente é a de 2017. O Projeto de Lei $\mathrm{n}^{\mathrm{o}}$ 6.787/2016 da Reforma Trabalhista foi proposto pelo então Presidente da República, Michel Temer, para alterar o Decreto-Lei $n^{\circ} 5.452$, de $1^{\circ}$ de maio de 1943 Consolidação das Leis do Trabalho, e a Lei $n^{0}$ 6.019, de 3 de janeiro de 1974, que dispunha sobre eleições de representantes dos trabalhadores no local de trabalho e sobre trabalho temporário, dentre outras providências. Em 2017, o PL foi transformado em Lei Ordinária: Lei $\mathrm{N}^{\mathrm{o}}$ 13.467, de 13 de julho de 2017. Esta lei incorpora alterações das Leis 8.036, de 11 de maio de 1990, e 8.212, de 24 de julho de 1991, para adequar a legislação às "novas" relações de trabalho.

As mudanças das formas de legalização do trabalho são expressões do movimento contraditório do discurso. Os documentos da legislação são a materialidade discursiva (subjetivação objetivada) em que se bloqueiam certos sentidos, como o de trabalho, em detrimento de outros, como trabalho ressignificado, emprego. É interessante observar como ele (o discurso do trabalho) é apropriado pelo capital em um processo de revisão semântica, cultural, social, econômica e política para se conformar às necessidades do capitalismo. Compreender o discurso da legislação é também compreender sua propriedade material discursiva, pois nela são produzidos os sentidos do trabalho para a sociedade.

\section{A MEMÓRIA NO DISCURSO DA ATUALIDADE: A EXPROPRIAÇÃO DO TRABALHO}

$\mathrm{Na}$ perspectiva da teoria materialista do discurso, o acontecimento discursivo também revela-se numa "situação concreta", mas não se encerra nela, porque, também, é processo, é contraditório, poderá não possuir uma "materialidade linguageira", da ordem da objetividade, do texto, da forma; mas tem a predominância da materialidade ideológica, da ordem do inconsciente, do conteúdo, produzindo efeitos de sentidos e interferindo na conduta, atitudes (práticas) dos indivíduos em sociedade. $\mathrm{O}$ acontecimento discursivo poderá não se manifestar em um único enunciado que tenha um referente, "a coisa no mundo", ou "um grito" que marque o acontecimento, assim como identificou Pêcheux (2006) ao analisar a expressão On a gagné na manifestação política da vitória de François Mitterand na França de 1981.

A proposta de Pêcheux em seu estudo é desestabilizar o referente que estaria preso à lógica formal sem que lhe fosse permitido deslizar sentidos da expressão referencial. $O$ "referente" seria referido, exclusivamente, como "a coisa no mundo", negando-se como ponto de deriva. Ora, é neste ponto de deriva que há a possibilidade de um sentido tornarse outro, de produção de efeitos de sentido outros. O ponto de deriva revela a contradição do discurso: ao afirmar, nega a si e ao outro do discurso, nega a sua memória discursiva, 
produzindo o que reconheço ser efeito de desmemória. Isso ocorre porque "há o outro na história correspondente a esse outro próprio ao linguareiro discursivo, que aí pode haver ligação, identificação ou transferência" (PÊCHEUX, 2006, p. 54). Este ponto de deriva permite que o discurso do capital sobre o trabalho, por exemplo, vele a expropriação do trabalho nos processos discursivos de emprego.

Então, a materialidade do discurso do direito ao trabalho pode ser encontrada em diferentes processos discursivos. O efeito desmemória pode ser identificado na queixa do trabalhador quando percebe apenas o efeito da expropriação: "Muita gente desempregada e o governo só pensa em cortar direito”, diz o pedreiro José Luís Junior (2019), referindose à reforma previdenciária. Ou na fala do empresário quando defende a criação de mais emprego, contribuindo para ocultar a destituição do trabalho assalariado no processo de produção capitalista dos tempos atuais. "A criação de empregos é fundamental para elevar a renda da população e incentivar o consumo das famílias e a retomada do crescimento econômico" - diz o Presidente da Confederação Nacional da Indústria [CNI], Robson Braga de Andrade (2019). Uma espécie de "apagamento da memória discursiva" - a desmemória - impede que se diga que o desemprego é intrínseco a essa fase do capitalismo; o emprego atingiu sua função máxima quando o trabalho concreto foi trocado por ele. Agora, há uma ressignificação do "emprego" da força de trabalho; novas modalidades de trabalho aparecem, ganham outros sentidos; o trabalho informal, por exemplo, cumpre a função de obscurecer a realidade do elevado índice do desemprego.

No Brasil de 2019 , mais de $26,2 \%$ dos desempregados procuravam trabalho (emprego) há no mínimo dois anos, o que equivalia a 3,347 milhões de pessoas nessa condição ${ }^{7}$. A pessoa que passa muito tempo procurando emprego e não o encontra vai trabalhar na informalidade, contribuindo para aumentar o índice do trabalho informal - o que corresponde a 41,4\% da população ocupada (o maior aumento desse setor desde 2016, indicando a quebra do contrato que foi historicamente substituindo o trabalho pelo emprego). População ocupada não é empregada, mas o discurso oficial do governo, que trata das estatísticas, utiliza este recurso para passar a informação de que o índice de desemprego diminuiu. No grupo do "trabalho informal" estão os trabalhadores sem carteira assinada (empregados do setor privado e domésticos), os sem CNPJ - Cadastro Nacional da Pessoa Jurídica (empregadores e por conta própria) - e os sem remuneração (auxiliam em trabalhos para a família). Os empregados sem carteira assinada totalizaram, no mês de agosto do ano de 2019, 11,8 milhões de pessoas, e os que trabalham por conta própria somaram 24,3 milhões de trabalhadores.

Nos discursos - do trabalhador e do empresário, como se viu -, podem aparecer elementos de sujeitos individuais, a queixa de um e o comprazimento do outro, mas são processos discursivos de um mesmo discurso cuja produção é determinada pela relação contraditória entre o sujeito que fala e o objeto falado. São diferentes discursos produzidos em condições reais diferentes nas quais se posiciona cada sujeito (trabalhador e empresário), mas dominados pelas mesmas condições de produção - a realidade capitalista. É essa realidade que articula processos discursivos "autorizados" por uma

\footnotetext{
7 “Esses números do segundo trimestre são os maiores desde 2012” (IBGE, 2019, disponível em https://agenciadenoticias.ibge.gov.br/agencia-noticias).
} 
formação ideológica (formação ideológica do capital ou formação ideológica do trabalho) ${ }^{8}$.

A materialidade do discurso do direito ao trabalho é, pois, não homogênea, está dispersa na prática social da sociedade; dá-se a perceber nas ruas, nas falas marcadas pelo sofrimento e pela desesperança - "Vai demorar muito para o povo conseguir se aposentar, deficientes e quem tem doença não vão conseguir beneficios. É uma maldade" (continuação do discurso do pedreiro L.J.J., expressão do discurso dos trabalhadores, que veem o elevado índice de desemprego). Enquanto isso, o discurso do capitalismo, representado por diversas instâncias, cria para a sociedade a ilusão de que o emprego vai voltar. Primeiro, foi a expropriação do trabalho; esgotada a carência da produção capitalista, descarta-se, agora, o emprego, expropriando-se com ele até mesmo o direito ao salário.

\section{SOBRE O SENTIDO DE EXPROPRIAÇÃO DO TRABALHO}

O acontecimento discursivo da expropriação do trabalho é um processo socio-histórico, diz respeito ao "trabalho concreto", trabalho individual realizado, exclusivamente, pelo e para o próprio trabalhador para a reprodução da sua vida e depois subordinado formalmente ao capital (MARX, 2004a). Cabe aqui examinar o sentido de expropriação para entender o seu efeito em relação ao trabalho concreto.

A palavra expropriação incorpora muitos sentidos em ambientes discursivos diversos. Muitas vezes anunciada em ocorrências discursivas do direito público, expropriação indica desapropriação, indenização ou transferência compulsória da propriedade para o poder público ${ }^{9}$, por interesse ou utilidade pública mediante prévia indenização do expropriado. O efeito metafórico ${ }^{10}$ produzido no discurso do trabalho pela transferência da propriedade no discurso do direito serve bem ao que estamos procurando demonstrar: a "transferência da propriedade" do trabalhador, a sua força de trabalho para o capitalista. O sentido de expropriação é constitutivo do sentido de desapropriação, indenização e transferência; a expropriação ancora-se nessas expressões e produz o "deslizamento de sentido" (PÊCHEUX, 1993, p. 96) que compreende o ato de expropriar. Nesta sociedade, $\mathrm{o}$ ato da administração pública para privar uma pessoa da titularidade de um bem (uma casa, um lote de terra, uma empresa) ou de um direito, compensando-lhe com uma indenização para reparar o dano, é legislado.

$\mathrm{O}$ ato de expropriação, em qualquer prática discursiva, sobretudo na legislativa, implicando desapropriação, é uma ação coerciva. Não se pode dizer que a pessoa que teve um bem expropriado tenha agido na qualidade de vendedor, porque é o capitalismo ou o poder público representado pelo Estado quem ordena a ação e estabelece as condições; por isso, é um ato unilateral, já que só uma das partes (representante da

\footnotetext{
${ }^{8}$ Sobre as duas formações ideológicas fundamentais da sociedade capitalista (formação ideológica do capital e formação ideológica do trabalho), ver Amaral (2005, 2016).

${ }^{9}$ No Brasil, o estatuto básico da desapropriação é o Decreto-lei $\mathrm{n}^{\circ} 3.365$, de 21 de junho de 1941, foi alterado com a Lei $\mathrm{n}^{\circ} 13.867$, de 26 de agosto de 2019, que acrescenta os requisitos da petição inicial e introduz a mediação e a arbitragem, por opção das partes, para a definição dos valores da indenização (HARADA, 2019).

${ }^{10}$ Assim como compreende Pêcheux (1993, p. 96): "o fenômeno semântico produzido por uma substituição contextual $[\ldots] "$.
} 
ideologia dominante) define as regras. Comumente, o objeto desapropriado tem uma materialidade; por exemplo, quando o Estado resolve demolir casas para construir uma rodovia, toma aquelas que estariam impedindo a construção sem que seus proprietários possam recusar. Neste caso, os proprietários recebem em troca uma indenização pelo bem que perderam.

Não é muito diferente no processo de expropriação do trabalho. Com o ato de expropriação amparado pelas leis da sociedade capitalista, o trabalho foi transferido compulsoriamente para o poder do capital. O acontecimento pode produzir efeitos de sentidos diferentes, mas o ato coercitivo é semelhante. Poder-se-ia dizer que a expropriação do trabalho é uma ação de desapropriação de uma "propriedade privada" o trabalho concreto -, no sentido positivo da propriedade privada, ao qual se refere Marx: "trabalho vivo", que produz valor de uso (produto utilizável), necessário à produção e à reprodução humana; é o trabalho como atividade social que dá ao indivíduo a condição de ser social. É na sociedade capitalista que o trabalho torna-se uma unidade complexa, adquire um segundo caráter: o trabalho abstrato (negativo), "trabalho morto", "trabalho pretérito", contido nas mercadorias, cujo principal fim é a criação de mais-valia, a valorização do valor, a reprodução e a autovalorização do capital.

O duplo caráter do trabalho (valor de uso e valor de troca) revela-se nas mercadorias, também incorporando o duplo modo de ser do trabalho: trabalho concreto, trabalho útil, que cria valor de uso concreto, necessário ao ser humano; e o trabalho abstrato, que gera valor de troca, excedente para o capital. Sintetizemos as ideias marxianas com Chagas (2012, p. 4).

\begin{abstract}
Enquanto o trabalho útil-concreto é qualitativo e cria os valores de uso necessários ao ser humano, para satisfazer socialmente as suas necessidades físicas e espirituais, o trabalho abstrato é, pura e simplesmente, quantitativo, a substância e a grandeza do valor, e produz mais-valia (valor excedente) para o capital.
\end{abstract}

Quando digo que o trabalho foi expropriado, refiro-me, fundamentalmente, à expropriação do trabalho concreto, à subtração da condição fundamental da própria existência humana do trabalhador, visto que somente por meio do trabalho positivo "o homem produz o homem e se produz a si mesmo e aos outros homens; como objeto, que constitui a atividade direta da sua personalidade, é ao mesmo tempo a sua existência para os outros homens e a sua existência para si" (MARX, 1989, p. 194). Nesse sentido, o trabalho é puramente individual. "Ao apropriar-se individualmente de objetos naturais para prover sua vida, é ele [o trabalhador] que controla a si mesmo; mais tarde ficará sobre o controle de outrem" (MARX, 1988, p. 584).

Apropriar-se individualmente dos proventos da vida por meio do trabalho, como se sabe, e Marx alerta para isso, não é uma prática adequada ao processo de produção capitalista. Neste processo, o trabalhador deixará de produzir para si; passará a produzir para o capital. $\mathrm{O}$ trabalho passa a incorporar um caráter negativo por se transformar em um meio para gerar mais quantidade, menos qualidade; sua finalidade original deverá ser esquecida, gerando um processo de desancoragem, não da expressão trabalho, mas da memória do trabalho. A "linhagem do trabalho" sofre uma ruptura para ter continuidade ancorada em outra forma (dialética do trabalho). Ocorre aqui o que Paveau (2015, p. 236) chama de amemória discursiva, uma derivação da memória discursiva, correspondendo 
a "apagamento, consciente ou inconsciente, de um passado ou de um legado discursivo, de formulações-origens sobre as quais o falante não gostaria de ter mais nada que dizer". É isso que acontece, o capitalismo persiste no apagamento do trabalho concreto, e assim cria a cultura do descarte - nada mais dura para sempre, tudo é descartável, tudo tem tempo de validade e não se fala mais nisso porque o tempo urge na intensa produção para alimentar o capitalismo. Produzir mercadoria para gerar excedente, mais-valia, é um discurso que torna o trabalhador sujeito da desmemória, do esquecimento necessário ao processo de produção capitalista "pelo fato de que lembrar-se 'ou ter em mente' seria insuportável". É por isso que podemos entender muito bem quando Marx (1988, p. 584) disse que "ser trabalhador produtivo não é nenhuma felicidade, mas azar".

No processo de trabalho do capital, o valor de uso experimenta "verdadeiro processo de transformação", até se decompor em meio de produção, condições objetivas do trabalho, e na capacidade de trabalho, condições subjetivas de trabalho. Marx ressalta: "o processo de trabalho no seu conjunto enquanto tal, na interação viva de seus elementos objetivos e subjetivos, apresenta-se como a forma total de valor de uso, isto é, uma forma real do capital no processo de produção" (MARX, 2004, p. 45-46). Aqui se pode perceber a contradição na relação capital x trabalho. No modo de produção capitalista, o trabalhador é usado como um instrumento de trabalho, agora transformado em mercadoria e valor, revestindo-se de trabalho concreto (valor de uso) e trabalho abstrato (produz excedente, gera mais-valia, é valor de troca). Assim, ele é empregado pelo capital no processo de produção até não ser mais necessário. Só para lembrar o processo contínuo de perdas do trabalhador:

\footnotetext{
o trabalho dos proletários perdeu, com a expansão da maquinaria e da divisão do trabalho, todo o carácter autônomo e, portanto, todos os atrativos. O proletário torna-se um mero acessório da máquina e dele se exige apenas o manejo mais simples, mais monótono, mais fácil de aprender. Assim, os custos do operário reduzem-se quase aos meios de subsistência de que necessita para o seu sustento e para a reprodução da sua espécie. O preço de uma mercadoria, portanto, o do trabalho também é, todavia, igual ao seu custo de produção. Logo, quanto mais cresce o caráter enfadonho do trabalho, mais se reduz o salário. (MARX, 1998, p. 13)
}

Assim, o trabalho foi subtraído do trabalhador e em seu lugar impuseram-lhe o emprego - trabalho assalariado. O sentido de trabalho deslizou para o sentido de emprego, produzindo um efeito metafórico (PÊCHEUX, 1993, p. 96) em que um incorpora o sentido do outro, mas preservam diferenças fundamentais. A expressão "emprego" é solidária à expressão "trabalho" porque dela depende para produzir sentido: não há emprego sem trabalho. O contrário é possível, o que torna o trabalho independente do emprego, embora sua finalidade original, de fazer prevalecer o valor de uso, também tenha sofrido alterações porque está impregnado pelo discurso-transverso (PÊCHEUX, 1997) do consumo de mercadoria. Pelo fato de o emprego preservar a zona de pertinência do trabalho em sua memória, mesmo que a desmemória opere no discurso do capital, no efeito de dominância dos discursos do trabalho e do emprego prevalece o efeito trabalho - trabalho ressignificado. $\mathrm{O}$ emprego prescreve e o trabalho permanece ressignificado: trabalho por conta própria, trabalho informal e outras modalidades dessa ordem. 
Martins (2012, p. 36), lembra que foi a Revolução Industrial que trocou o trabalho por emprego. Foi aí que "os trabalhadores, de maneira geral, passaram a trabalhar por salários". O salário é o elemento que caracteriza, fundamentalmente, a mudança de trabalho para emprego. O emprego aparece, assim, como uma recompensa, um prêmio de consolação para o trabalhador. Com um emprego, o trabalhador julga-se compensado, uma espécie de indenização por lhe terem tirado a "propriedade privada" (o trabalho, no sentido positivo), por meio da qual poderia conduzir e reproduzir a sua vida, agora tornado em "acessório da máquina", como o disse Marx quando observava os trabalhadores na fábrica. Aquele acontecimento também se transformou: o sentido de "trabalhadores de fábricas" deslizou para o sentido de "trabalhadores da indústria moderna", como podemos ver em Marx (1998, p. 13):

a indústria moderna transformou a pequena oficina do mestre patriarcal na grande fábrica do capitalista industrial. Massas de operários, reunidos em fábrica, são organizadas como exércitos. São colocados, como soldados rasos da indústria, sob a vigilância de uma hierarquia completa de sargentos e oficiais. Não são apenas servos da classe burguesa, do Estado burguês: dia a dia, hora a hora, são servos da máquina, do contramestre e, sobretudo, de cada um dos burgueses industriais. E esse despotismo é tanto mais mesquinho, mais odioso, mais exasperador, quanto mais abertamente proclama ser o lucro como sua finalidade exclusiva.

Com o desenvolvimento da sociedade moderna, da tecnologia, da robótica, novas condições são impostas para os trabalhadores que se veem ressignificados em empregados/desempregados modernos. Do trabalhador, exige-se mais qualificação, embora sejam poucos os que conseguem acompanhar o processo da produção capitalista da atualidade. Os órgãos representantes dos setores produtivos do Brasil, como a CNI (Confederação Nacional da Indústria), por exemplo, põem a questão da seguinte maneira:

Estamos tratando também de infraestrutura contemporânea, que é rede de dados $5 \mathrm{G}$, capazes de estimular e suportar o desenvolvimento de tecnologias que usem esse tipo de infraestrutura, principalmente para a indústria 4.0. Robôs cirúrgicos, por exemplo. Para avançarmos nesse campo, precisamos de uma rede muito rápida, segura e sem quedas, que permita a comunicação de quem está no comando e o robô, que pode ser feito inclusive à distância. Esse é um fator importante para sermos mais competitivos no longo prazo. (NEGRI, 2019, Entrevista, online)

Então, hoje, um novo deslizamento de sentidos identifica os trabalhadores como "empregados modernos" que correm o risco de permanecerem desempregados ou trabalharem na informalidade se não acompanharem o desenvolvimento tecnológico do capitalismo. Essa é uma questão mais complexa, remete à política de formação da força de trabalho, da educação no país, que não poderá ser tratada aqui. Diremos, contudo, com Marx, que

não basta que haja, de um lado, condições de trabalho sob a forma de capital e, de outro, seres humanos que nada têm para vender além de sua força de trabalho. Tampouco basta forçá-los a se venderem livremente. Ao progredir a produção capitalista, desenvolve-se uma classe trabalhadora que por educação, tradição e costume aceita as 
exigências daquele modo de produção como leis naturais evidentes. (MARX, 1985, p. 854)

Isso significa que o trabalhador internaliza a exploração do modo de produção capitalista como algo natural. Não é simplesmente porque não dispõe de nenhum outro bem que não seja a sua força de trabalho e se submete à condição de explorado; ele aceita como legítima e legal a troca do trabalho pelo salário, vivencia essa realidade concretamente. Disso deduz-se que na sociedade capitalista o ente trabalhador é o ser assalariado.

Assim, consolida-se o processo de expropriação do trabalho do sujeito trabalhador na sociedade do capital. É justamente nesse momento histórico do modo de produção capitalista que se criam as políticas e as leis para sistematizar o trabalho livre e subordinado, expressando-se a complexa contradição que se instala no processo produtivo: afirma-se o trabalho livre ao tempo em que o nega e o subordina às condições de produção reestruturadas e ressignificadas. A troca do trabalho pelo emprego trouxe insegurança, incertezas para o trabalhador, fragilizando, sobremaneira, a sua vida reprodutiva. A expropriação do trabalho, pois, está relacionada à condição de inoperância à qual é submetido o trabalhador; à condição de desalentado ${ }^{11}$ imposta pela sociedade capitalista ao trabalhador desempregado quando lhe roubou o trabalho.

\section{ANIQUILAÇÃO DO EMPREGO SOB O EFEITO “AUTONOMIA" DO TRABALHADOR E A DESMOBILIZAÇÃO DO TRABALHADOR}

Quando o trabalho foi transformado em emprego e o salário surgiu como uma recompensa, o trabalhador julgou-se livre, convenceu-se pelo discurso do capital que seria capaz de escolher, entre as ofertas do mercado, aquela que mais valorizasse a sua força de trabalho. A sociedade formulou e fez circular os discursos que fizeram apologia ao mercado de trabalho, produziu efeitos metafóricos de "paraíso" em uma sociedade pautada por uma ideologia que aciona sentidos de liberdade, igualdade, propriedade $e$ Bentham, como diz Marx (1988, p. 196):

Liberdade, pois o comprador e o vendedor de uma mercadoria, a força de trabalho, por exemplo, são determinados apenas pela sua vontade livre. Contratam como pessoas livres, juridicamente iguais. $\mathrm{O}$ contrato é o resultado, a expressão jurídica comum das vontades. Igualdade, pois estabelecem relações mútuas apenas como possuidores de mercadorias e troca equivalente. Propriedade, pois cada um só dispõe do que é seu. Bentham, pois cada um dos dois só cuida de si mesmo. A única força que os junta e os relaciona é a do proveito próprio, da vantagem individual, dos interesses privados. (os grifos são nossos)

Mas isso também está mudando. As ideias de Jeremy Bentham (1748-1832) acerca do utilitarismo, cujo discurso combina política conservadora ${ }^{12}$ com elementos liberais,

\footnotetext{
${ }^{11}$ Segundo o IBGE, desalentado é o trabalhador desempregado que não está procurando emprego. Pessoas que perderam o emprego desistiram por não conseguirem retornar ao mercado de trabalho.

12 As ideias conservadoras do século XVIII, defendidas, entre outros, por Edmund Burke, sustentam o pensamento predominante do conservadorismo atualmente. Elas foram reforçadas e ressignificadas por muitos "ideólogos" que argumentaram e deram margem ao fortalecimento do liberalismo e seus princípios
} 
representando a ideologia de princípios conservadores que delegam às pessoas a responsabilidade de se tornarem, por vontade própria, submissas às leis do capitalismo, estão se fortalecendo sob novas estruturas. Aquela ideia de que cada pessoa seria, ao mesmo tempo, seu próprio vigia e vigia dos outros, e todos se comportariam como se estivessem sendo permanentemente vigiados, agora ganha novo sentido porque o trabalho abstrato está predominando sobre o trabalho concreto. $\mathrm{O}$ adestramento dos indivíduos para atender à produção nas fábricas tem sua finalidade deslocada: adestra-se para se adaptar fora das fábricas, para ser trabalhador autônomo, para ficar sem o emprego da fábrica. O sistema pedagógico conhecido como panóptico ${ }^{13}$, físico e geograficamente demarcado, tornou-se um sistema virtual, invisível, imaginário, exercendo um controle muito mais profundo no campo da subjetividade e da consciência dos trabalhadores, tanto que o sentido de classe é afetado pelo efeito desmemória.

O controle da produção baseado no sistema de um panóptico produziu um efeito de ampliação e fortalecimento do princípio liberal de liberdade. A relação de poder que se estabeleceu por meio de contratos reproduziu o discurso da vontade em que as partes podiam fazer acordos que aparentavam livre e espontâneo interesse individual. $\mathrm{Na}$ sociedade do emprego, o trabalho passou a ser instruído pelo discurso da moral pública: fazer crescer e multiplicar sob a autodeterminação, sob a responsabilidade sobre si mesmo, sob o slogan do empreendedorismo. O discurso da pedagogia liberal para disciplinar o trabalho, redefinindo-o como emprego, esforçou-se para fortalecer o discurso de liberdade individual e compromisso com o sucesso da empresa. Por sua vez, o discurso do emprego produziu efeitos de comprometimento e fidelidade, iludindo o trabalhador acerca da homogeneização do poder no espaço do trabalho. Produziu um sentido de poder que elevou o imaginário do sujeito empregado à condição de igualdade, por julgar-se em condições de troca equivalente às do seu empregador e às dos sujeitos da equipe da qual era parte na empresa.

O discurso do trabalho sobrevive sob a forma de um efeito trabalho no discurso do emprego, silenciado no acontecimento de desmemória discursiva. A expropriação do trabalho concreto se repete como expropriação do emprego na medida em que o capitalismo rompe com o contrato de trabalho assalariado por tê-lo esgotado, procurando criar outras formas de recompensa. O acontecimento que transformou o trabalhador em empregado, que deu ao emprego o sentido de trabalho e deste abstraiu seus nexos ontológicos para dar vez aos elementos capitalistas de controle do sujeito trabalhador está em processo de ressignificação. Hoje os espaços de trabalho são restritos, privados, circunscritos pelo discurso das leis trabalhistas; são círculos sem saídas que aprisionam o trabalhador à condição de empregado sob vigilância virtual. Os antigos espaços produtivos designados de empresas se transformaram em espaços fluidos e virtuais. Espaços físicos foram fechados, atividades foram informatizadas, empregados foram requalificados e novos paradigmas de trabalhadores foram requisitados pelo mercado de trabalho.

Aquela moderna estrutura da empresa na forma de um panóptico foi ressignificada em decorrência de todas as mudanças que afetaram a classe trabalhadora. Rôney Rodrigues

fundamentais como o do utilitarismo, construindo as bases para o conservadorismo moderno (AMARAL; HAURADOU, 2019).

${ }^{13}$ Assim como diz Kurz (1997): um princípio de controle e gestão de pessoas identificado na organização do trabalho por Bentham, no século XIX. 
(2019) faz uma pergunta muito instigante quando trata da nova morfologia da classe trabalhadora e da crise dos sindicatos: "A classe trabalhadora vai ao inferno?" É interessante observar essa classe, pois, conforme diz o autor, "[ela] não é mais representada por operários manejando equipamentos industriais e vestidos com macacões". A nova classe trabalhadora estaria perdendo suas características históricas de luta devido à dificuldade de organização de trabalhadores digitais, terceirizados, dispersos em muitas ocupações, prestadores de serviços, autônomos, em atividades domésticas, por conta própria, com acordos feitos com empregadores difusos, quase invisíveis.

A "nova CLT", ajustada às exigências da sociedade atual com a Lei n' 13.467 , publicada em 14 de julho de 2017, em vigor desde 11 de novembro daquele mesmo ano, é tida pelos empresários como um avanço sem prejuízo para os trabalhadores; é o que expressa a Confederação Nacional do Comércio de Bens, Serviços e Turismo - CNC (2017) -, ao dizer que as mudanças são adequações "ao avanço socioeconômico e tecnológico ao qual chegou a sociedade brasileira, sem a extinção de direitos dos trabalhadores". O autor faz um resumo do que julga ser benefícios das mudanças, e destaca:

[...] a prevalência do negociado sobre o legislado; a valorização dos acordos individuais entre patrões e empregados; a possibilidade de novas formas de contratação (exemplo: o contrato de trabalho intermitente); a criação de regras para o teletrabalho; o fim das horas in itinere; a terceirização das atividades meio e fim; a utilização da arbitragem para os trabalhadores cuja remuneração seja superior a duas vezes o limite máximo estabelecido para os benefícios da Previdência Social; a representação dos trabalhadores no local de trabalho nas empresas com mais de 200 empregados; a duração de dois anos da convenção ou acordo coletivo de trabalho com vedação da ultratividade; e a criação do termo de quitação anual de obrigações trabalhistas.

O teletrabalho é uma demonstração do processo de deslocamento do sentido de trabalho, novas modalidades de trabalho e de contratos, como o terceirizado e o trabalho intermitente, do presencial para o não presencial com características de trabalho virtual, invisível. Consta na CLT, art.75-B: "Considera-se teletrabalho a prestação de serviços preponderantemente fora das dependências do empregador, com a utilização de tecnologias de informação e de comunicação que, por sua natureza, não se constituam como trabalho externo". É o trabalho fora das vistas do patrão. "Quem é o patrão de aplicativos como Uber, 99Taxi, Rappi e iFood?", pergunta feita por Rodrigues (2019), refletindo sobre as dificuldades de os sindicatos representarem e protegerem os direitos desses trabalhadores.

Vê-se em espaços delimitados, como os escritórios ou as fábricas, que o discurso pedagógico para o trabalho é controlado, voltado para o empregado com uma ocupação definida; incorpora um discurso pedagógico destinado ao trabalhador volátil, arbitrário. As formas de controle são ressignificadas, o controle do sujeito é feito diretamente na dimensão subjetiva. As empresas, ressignificadas, sofisticaram as formas de controle da subjetividade dos trabalhadores, transformaram as prisões, oficinas, fábricas, hospitais, reformatórios dos tempos passados em espaços virtuais pulverizados de medo e insegurança, agravados pelo fato de não se ter à frente quem combater. Como lutar com um patrão virtual? A luta será, pois, contra si próprio; daí decorre o autoflagelo, o 
desalento, as desesperanças. Mesmo atualmente, quando o discurso sobre o trabalho propõe a mudança dos nomes para designar quem trabalha, na memória desses dizeres pode-se identificar o sentido de subserviência, abnegação. É o que se pode ver nas convocações ditas "mais modernas", que tratam os empregados como parceiros, colaboradores, associados. O discurso sobre o trabalho é marcado com uma série de lacunas, de desvios, de "substituições", produzindo efeitos de mudanças nas relações de trabalho, apontando para uma unidade entre os sujeitos, pautada nos princípios de igualdade e de liberdade; mas é nesses temas que se pode apreender a incompatibilidade do que é diferente.

\section{CONSIDERAÇÕES FINAIS}

Como vimos anteriormente, neste artigo, os dados oficiais do discurso sobre o emprego/trabalho não revelam as razões do desemprego. O que podemos ver é um novo desenho do quadro de trabalhadores no Brasil: tiveram seus trabalhos transformados em empregos e agora veem seus empregos diluídos, transformados em modalidades de trabalho ditas modernas, sem emprego - fortalecido pelo discurso do trabalho autônomo, do empreendedorismo. Este é um acontecimento discursivo do trabalho que põe novas configurações do capitalismo. Silenciando o processo de expropriação do trabalho, tal acontecimento estimula o discurso da liberdade, do acordo e da negociação entre capital e trabalho, conduzindo o trabalhador à "aceitação dos novos tempos", à aceitação das "evidências" produzidas pela ideologia.

Os trabalhadores são hoje na sociedade capitalista sujeitos expropriados do direito ao trabalho; sua voz foi emudecida pelos interesses do lucro e do consumo, sobrepostos às reais necessidades dos homens para se manterem vivos. Esse é um quadro sobre o qual Engels discorria em tempos de capitalismo do século XIX. Então, com Engels, dou uma pausa em nossas reflexões para continuar procurando entender o acontecimento do trabalho neste século XXI.

Entrementes, em cada inverno, renova-se a pergunta: "O que fazer com os desempregados?" Enquanto se avoluma, cada ano, o número deles, não há ninguém para responder a essa pergunta; e quase podemos prever o momento em que os desempregados perderão a paciência e encarregar-se-ão de decidir seu destino, com suas próprias forças. (ENGELS, [1886], 1988, p. 29).

\section{REFERÊNCIAS}

ALTHUSSER, Louis. Ideologia e Aparelhos Ideológicos de Estado (Notas para uma investigação) (1970). Em: ZIZEK, Slavoj (Org.). Um Mapa da Ideologia. Rio de Janeiro: Contraponto, 1996. p. $105-142$.

AMARAL. M.V.B.; HAURADOU. G.R. A Reiteração do conservadorismo e as possibilidades de enfrentamento no Serviço Social. Anais do XVI Encontro Nacional de Pesquisadores em Serviço Social, $\quad$ v. $16 \quad$ n. $1, \quad 2018 . \quad$ Disponível em http://www.periodicos.ufes.br/?journal=abepss\&page $=$ article\&op=view\&path[] $=26252$. Acesso em 15 out. 2019.

AMARAL. M.V.B. Discurso e relações de trabalho. Maceió: Edufal, 2005, 2016. 
AMARAL. M.V.B. O Avesso do Discurso: análise de práticas discursivas no trabalho. Maceió: Edufal, 2007.

ANDRADE, Robson Braga de. Posicionamentos. Disponível em https://noticias.portaldaindustria.com.br/posicionamentos/. Acesso em 18 de out. de 2019.

BRASIL. [Constituição (1988)] Constituição da República Federativa do Brasil. 35a . ed. Brasília: Câmara dos Deputados, Edições Câmara, 2012.

CONFEDERAÇÃO NACIONAL DO COMÉRCIO DE BENS, SERVIÇOS E TURISMO CNC. A Reforma Trabalhista. A Nova Consolidação das Leis do Trabalho. Setembro de 2017. Disponível

http://cnc.org.br/sites/default/files/arquivos/cartilha reformatralhista interativa_0.pdf. Acesso em 3 out. 2019.

BRASIL. Consolidação das leis do trabalho - CLT e normas correlatas. Brasília: Senado Federal, Coordenação de Edições Técnicas, 2017.

CHAGAS, E.F. A determinação dupla do trabalho em Marx: trabalho concreto e trabalho abstrato, 2012. Disponível em https://marxismo21.org/wp-content/uploads/2012/08/Adetermina\%C3\%A7\%C3\%A3o-dupla...-Ed.-Chagas.pdf. Acesso em 17 nov 2019.

COURTINE, J.-J. Quelques problèmes theóriques et méthodologiques en analyse du discours: à propos du dicours comuniste adressá aux chrétiens. Langages, 62, Paris, Larousse, 9-127, 1981. ENGELS, F. [1886]. Do socialismo utópico ao socialismo científico. São Paulo: Global. 1988. HARADA, K. Alterações na lei de desapropriação. Revista Jus Navigandi, Teresina, ano 24, n. 5916, 12 set. 2019. Disponível em https://jus.com.br/artigos/76258. Acesso em 16 fev. 2020.

INSTITUTO BRASILEIRO DE GEOGRAFIA E ESTATISITCA [IBGE]. Página disponível em www.ibge.gov.br; https://agenciadenoticias.ibge.gov.br/agencia-noticias. Acesso em 12 out. 2019.

JUNIOR. L.J. Trabalhadores lotam a Sé em protesto contra reforma da Previdência. Disponível em https://spbancarios.com.br/02/2019/trabalhadores-lotam-se-em-protesto-contra-reforma-daprevidencia. Acesso em 18 out. 2019.

KURZ, Robert. Os últimos combates. Rio de Janeiro, Vozes, 1997.

MARTINS. Sergio Pinto. Direito do trabalho. $28^{\mathrm{a}}$ ed. São Paulo: Adas, 2012.

MARX, K.; ENGELS, F. A ideologia alemã. São Paulo: Cortez, 1986.

MARX, K.; ENGELS, F. Cartas - Marx a P.V. Annenkov. Em: Obras escolhidas. São Paulo: Alfa-ômega, s/d, p. 244-253.

MARX, Karl. Capítulo VI [inédito de O Capital]. São Paulo: Centauro, 2004a.

MARX, Karl. Processo de Trabalho e Processo de Valorização. Em: ANTUNES, R. (Org.). A

Dialética do Trabalho. São Paulo: Expressão Popular, 2004b.

MARX, Karl. (1948). O manifesto do partido comunista. São Paulo, Cortez, 1998.

MARX, Karl. A questão judaica. São Paulo: Editora Moraes, 1988.

MARX, Karl. O Capital. Livro I, vol. I. 12 ${ }^{\mathrm{a}}$ ed. Rio de Janeiro: Bertrand Brasil, 1988.

MARX, Karl. Manuscritos Econômico-Filosóficos. Textos filosóficos. Lisboa, Portugal: Edições 70, 1989.

MARX, Karl. Contribuição à crítica da economia política. São Paulo: Martins Fontes, 1983

NEGRI, Fernanda de. Inovação é chave para Brasil melhorar produtividade [Entrevista cedida a] Darse Júnior, Agência de Notícias da Confederação Nacional da Indústria. Disponível em http://www.portaldaindustria.com.br/cni/. Acesso em 17 out. 2019.

PAVEAU. M.-A. Linguagem e Moral: uma ética das virtudes discursivas. Campinas: Editora da Unicamp, 2015.

PÊCHEUX M.; FUCHS C. A propósito da análise automática do discurso: atualização e perspectivas. Em: GADET, F.; HAK, T. (Orgs). Por uma análise automática do discurso. Uma introdução à obra de Michel Pêcheux. $2^{\mathrm{a}}$ ed. Campinas: Editora da Unicamp, 1993.

PÊCHEUX, M. O discurso: estrutura ou acontecimento. Campinas: Pontes, 1990.

PÊCHEUX, M. (1975). Semântica e Discurso: uma crítica a afirmação do óbvio. Campinas: Editora da Unicamp, 1988 e 1997.

PÊCHEUX, M. O mecanismo do (des)conhecimento ideológico. Em: ZIZEK, S. (Org.). Um Mapa da Ideologia. Rio de Janeiro: Contraponto, 1996. 
PEREIRA, S.N.; RANGEL, T.L.V. O trabalho como direito fundamental. Boletim Jurídico, Uberaba, MG, a. 13, n. 1538. Disponível em https://www.boletimjuridico.com.br/ doutrina/artigo/4652/o-trabalho-como-direito-fundamental. Acesso em 17 out. 2019.

RODRIGUES, R. Sindicatos: a classe trabalhadora vai ao inferno? Disponível em https://outraspalavras.net/movimentoserebeldias/sindicatos-da-crise-vira-a-reinvencao/. Acesso em 18 de out. de 2019.

RASSI, A.P. Do acontecimento histórico ao acontecimento discursivo: uma análise da "Marcha das vadias". Revista de História da UEG, Goiânia, v. 1, n. 1, 43-63, jan./jun. 2012.

UNESCO/Brasil (1948 [1998]). Declaração Universal dos Direitos Humanos. Disponível em https://nacoesunidas.org/wp-content/uploads/2018/10/DUDH.pdf. Acesso em 20 de nov. de 2019.

Artigo recebido em: out. de 2019.

Aprovado e revisado em: nov. de 2019.

Publicado em: dezembro de 2019.

Para citar este texto:

AMARAL, Maria Virgínia Borges. O discurso do trabalho e suas múltiplas expressões materiais e ideológicas. Entremeios [Revista de Estudos do Discurso, ISSN 2179-3514, on-line, www.entremeios.inf.br], Seção Estudos, Programa de Pós-Graduação em Ciências da Linguagem (PPGCL), Universidade do Vale do Sapucaí (UNIVÁS), Pouso Alegre (MG), vol. 20, Especial, Dossiê "Língua, discurso e trabalho na contemporaneidade", p. 85-100, dez. 2019.

DOI: http://dx.doi.org/10.20337/ISSN2179-3514revistaENTREMEIOSvol20pagina85a100 